\title{
Do cognitive psychologists share a paradigm? A second look
}

\author{
PATRICIA HOLLEY and JANET STACK \\ University of South Florida, Tampa, Florida
}

(James J. Jenkins, Sponsor)

\begin{abstract}
The purpose of this study was to look at the degree of overlap of index headings and subheadings in five second editions of cognitive psychology textbooks. The results indicated that a very slight overlap of items was present between the textbooks, with most items unique to a single one. Furthermore, some same headings referred to different topics, and some different headings referred to the same topic. These findings are discussed with regard to Kuhn's (1970) theory of paradigm evolution.
\end{abstract}

According to Kuhn (1970), “A paradigm stands for the entire constellation of beliefs, values, techniques, and so on shared by the members of a given community" (p. 175). Normal science emerges through stages beginning with a pre-paradigm period. During the pre-paradigm period, there is little consensus between competing schools of theory. Each school makes its own significant contribution toward the development of the paradigm; however, each will not take a common body or belief for granted. Accordingly, during this time period, all facts seem to be equally relevant. As the paradigm converges, there will be a formation of specialized journals and societies and a special place in the curriculum (p. 19). With the formation of a paradigm, scientists can begin to examine more esoteric and subtle aspects of the phenomena on the basis of a common, generally accepted core of concepts, methods, language, and so forth.

In a study designed to look at whether cognitive psychology could be considered a Kuhnian "paradigm," White (1985) looked at the degree of overlap in reference lists for seven prominent undergraduate textbooks in cognitive psychology, all published in 1979 or 1980 . He found that only $1 \%$ of the references were common to all seven texts. Thus, using this finding along with other data, he concluded that cognitive psychology was pre-paradigmatic, that is, that it lacked a core of widely accepted findings.

In 1989, Robert Dale and Barbara Cochran wanted to determine if the situation had improved in second editions of the books used by White (1985) and thus to see if the field had converged to a more common body of knowledge. They examined five textbooks having both first and second editions (four of which were from White's original list). In their study, they expected to find much more agreement between reference lists of the second editions as compared with the first editions. The first editions used

Correspondence may be addressed to Janet W. Stack, Department of Psychology, University of South Florida, Tampa, FL 33620. were published between 1979 and 1982; second editions were published between 1985 and 1988. Their findings were surprising in that they found no increase in the proportion of common citations between the first and second editions of the texts. There were many changes and additions in the references used but no sign of increase in convergence in the 7 years between the first and second editions. They concluded, in agreement with White, that "cognitive psychology has some way to go before it assumes the mantle of normal science"' (White, 1985, pp. 118-119).

A question that arose from these findings was whether a reference list projects a true impression of the subject matter being presented. It is possible that there is considerable overlap in topics being discussed in the textbooks, but that different studies and references are used by different authors to address the same issues. If there is a common body of knowledge being presented, it would seem reasonable that textbooks would share topics of interest to the field and that index headings would show a great deal of overlap. This study was an attempt to discover if, in fact, index headings and subheadings do have a great deal of overlap, thus showing that cognitive psychology does have a more common body of knowledge than suggested by overlap of reference lists.

\section{METHOD}

We examined the second editions of the five textbooks used by Dale and Cochran (1989). These were: Anderson, J. R. (1985), Cognitive psychology and its implications; Bourne, L. E., Jr., Dominowski, R. L., Loftus, E. F., \& Healy, A. F. (1986), Cognitive processes; Glass, A. L., \& Holyoak, K. J. (1986), Cognition; Reed, S. K. (1988), Cognition; and Solso, R. L. (1988), Cognitive psychology.

All main headings and subheadings in the indexes of all five books were combined into one alphabetically arranged master list (available on request). This was done by going through each index, item by item, and entering them one at a time into a computer. Five columns were then created, one for each book, and when a book contained one of the items as a main heading in its index, it was marked with an " $x$." When a book contained one of the items as a subheading, it was marked with an "o." For example, Reed (1988) listed "bottleneck theories" as a subheading under the main heading of "attention." In Solso (1988), 
"bottleneck theories" was a main index heading. By referring to this master list, it was possible to see where overlap in index items does or does not occur in the five books and with what frequency. For example, it can be seen in the first page of this master list that "ACT" was found as a main heading in three of the five books. Calculations were then made of the frequency with which individual items appeared in all five books, in four books, and so on.

\section{RESULTS}

There were a total of 928 items listed in all five textbooks. Of these, only $19(2 \%)$ were common to all five (list available on request). Interestingly, this is close to the same percentage of overlap found by Dale and Cochran (1989) when using reference lists (1\%). There were 34 items $(4 \%)$ common to four of the textbooks. There were 66 items (7\%) common to three of the textbooks and 138 items (15\%) common to two texts. Of all the items listed, 671 , or $72 \%$, were unique to one of the five textbooks.

In addition to the surprising lack of common topics found in the indexes, it should be noted that there are several instances where the same heading is used to describe quite different topics. For example, the heading "analog representations" in Glass and Holyoak (1986) refers to decision making; whereas in Anderson (1985), it refers to spatial images. Alternately, there are instances where different headings are used to represent the same topic. For example, "color categories," listed in both Glass and Holyoak (1986) and Bourne et al. (1986), deals with the same topic as "color discrimination" listed in Reed (1988). It is clear that there is not only a lack of common topics, but furthermore, that the language used is not always consistently defined.

\section{DISCUSSION}

As with both White (1985) and Dale and Cochran (1989), there is very little overlap between the five textbooks examined in either their reference lists or, as evidenced by this study, their indexes. It appears, therefore, that not only do textbooks cite different studies and authors, they also place importance on different topics. Furthermore, they also seem to disagree on a common language of terminology when referring to a single topic and occasionally use the same language to refer to different topics. These findings, taken together, seem to indicate that cognitive psychology is in the throes of pre-paradigmatic evolution as defined by Kuhn (1970). It would be interesting to determine whether this is unique to cognitive psychology by making a similar analysis of other areas of psychology, such as the social psychology literature or the personality literature. Additionally, it would be worthwhile to investigate other areas of science, such as physics or chemistry, where certain areas have been established for study for a number of years, to see how such an analysis compares.

\section{REFERENCES}

ANDERson, J. R. (1985). Cognitive psychology and its implications (2nd ed.). San Francisco: Freeman.

Bourne, L. E., JR., Dominowski, R. L., Loftus, E. F., \& Healy, A. F. (1986). Cognitive processes (2nd ed.). Englewood Cliffs, NJ: Prentice-Hall.

Dale, R. H., \& Cochran, B. P. (1989). Do cognitive psychologists share a paradigm? Paper presented at the 30th Annual Meeting of the Psychonomic Society, Atlanta.

Glass, A. L., \& Holyoak, K. J. (1986). Cognition (2nd ed.). Reading, MA: Addison-Wesley.

KuHN, T. S. (1970). The structure of scientific revolutions (2nd ed.). Chicago: University of Chicago Press.

ReED, S. K. (1988). Cognition (2nd ed.). Monterey, CA: Brooks/Cole. Solos, R. L. (1988). Cognitive psychology (2nd ed.). New York: Harcourt Brace Jovanovich.

WHITE, J. J. (1985). On the status of cognitive psychology. American Psychologist, 40, 117-119.

(Manuscript received August 9, 1991.) 